SHORT COMMUNICATION

\title{
Morphology, morphometry and ultrastructure of the Amazonian manatee (Sirenia: Trichechidae) spermatozoa
}

\author{
Rodrigo S. Amaral', 5; Carolina M. Lucci²; Fernando C. W. Rosas³; \\ Vera M. F. da Silva ${ }^{3} \&$ Sônia N. Báo ${ }^{4}$
}

\author{
${ }^{1}$ Departamento de Reprodução Animal, Faculdade de Medicina Veterinária e Zootecnia, Universidade de São Paulo. \\ 05508-270 São Paulo, SP, Brazil. \\ ${ }^{2}$ Faculdade de Agronomia e Medicina Veterinária, Universidade de Brasília. 70919-970 Brasília, DF, Brazil. \\ ${ }^{3}$ Laboratório de Mamíferos Aquáticos, Instituto Nacional de Pesquisas da Amazônia. 69083-001 Manaus, AM, Brazil. \\ ${ }^{4}$ Laboratório de Microscopia Eletrônica, Instituto de Ciências Biológicas, Universidade de Brasília. $70919-970$ Brasília, \\ Distrito Federal, Brazil. \\ ${ }^{5}$ Corresponding author. Email: rsamaral@usp.br
}

\begin{abstract}
This study describes the morphological, morphometric and ultrastructural characteristics of the Amazonian manatee Trichechus inunguis (Natterer, 1883) spermatozoon. The spermatozoa were obtained from a urine sample of an adult $T$. inunguis kept in captivity. The spermatozoa were analyzed by light and transmission electron microscopy. The head of Amazonian manatee spermatozoa had a flat oval shape and a well distinguishable midpiece. The mean dimensions of the spermatozoa were: head length, $7.49 \pm 0.24 \mu \mathrm{m}$; head width, $3.53 \pm 0.19 \mu \mathrm{m}$; head thickness, $1.61 \pm 0.13 \mu \mathrm{m}$; midpiece length, $11.36 \pm 0.34 \mu \mathrm{m}$; flagellum length, $40.91 \pm 1.94 \mu \mathrm{m}$; total tail length, $52.16 \pm 1.06 \mu \mathrm{m}$; total spermatozoon length, $60.08 \pm 1.40 \mu \mathrm{m}$. The Amazonian manatee spermatozoa were similar in shape to other sirenian spermatozoa; however, presenting a different size. This study describes, for the first time, the morphometric and ultrastructural characteristics of the Amazonian manatee spermatozoa, and also demonstrates the possible use of spermatozoa retrieved from urine samples for biological studies.
\end{abstract}

KEY WORDS. Anatomy; reproduction; sirenians; spermatozoon; Trichechus inunguis.

Morphological and ultrastructural analysis of spermatozoa are useful tools in reproductive biology and phylogenetic studies of several species, being utilized to contribute characters for phylogenetic analysis, evaluate mating strategies, and develop new reproductive technologies or improve existing ones (Anderson et al. 2005, Luque \& BÁo 2006, Plön \& Bernard 2006).

The Amazonian manatee Trichechus inunguis (Natterer, 1883) is a threatened aquatic mammal, endemic of the Amazon basin, and is the only sirenian that occurs exclusively in fresh water (BEST 1984, RosAs 1994). It is the smallest sirenian, measuring up to $2.8 \mathrm{~m}$ and weighing $450 \mathrm{~kg}$ (Husar 1977, Rosas 1994). Although certain aspects of Amazonian manatee biology have been well studied, there is an absence of basic information about the reproductive anatomy and physiology of this species.

The aim of this study was to contribute to the knowledge of the Amazonian manatee reproductive biology presenting the morphological, morphometric and ultrastructural characteristics of its spermatozoon.

The spermatozoa were observed in urine samples collected from a healthy adult $T$. inunguis.
While spermatozoa were observed in more than one urine sample, only one urine sample was analyzed in this study.

The urine sample was centrifuged (1000 RPM, $10 \mathrm{~min}$ ), the pellet was washed with saline solution $(0,9 \% \mathrm{NaCl})$ and centrifuged again at the same speed and time. A portion of the pellet was fixed with $10 \%$ formalin solution for light microscopy analysis and the other portion was fixed with $2 \%$ paraformaldehyde and $2.5 \%$ gluteraldehyde in phosphate buffer for transmission electron microscopy analysis. The formalin fixed sample was analyzed and photographed with a phasecontrast microscope (Zeiss, Oberkochen, Germany). Measurements of head length, width and thickness, midpiece length, tail length and total length were taken from 100 spermatozoa using the software Image Pro Express 6.0 (Media Cybernetics Inc., Bethesda, MD, USA). The paraformaldehyde/glutaraldehyde fixed sample was rinsed with a sodium cacodylate buffer (0.1M, pH 7.3), and post-fixed with $1 \%$ osmium tetroxide, $0.8 \%$ potassium ferricyanide and $5 \mathrm{mM}$ calcium chloride in a sodium cacodylate buffer. After which, it was dehydrated in a series of ascending concentrations of acetone solutions (30- 
$100 \%)$ and embedded in Spurr epoxy resin. Ultrathin sections were cut, stained with uranyl acetate and lead citrate, then observed and photographed using a transmission electron microscope (Jeol 1011, Jeol, Tokyo, Japan).

The head of the Amazonian manatee spermatozoa had a flat oval shape and the acrosome covered approximately threequarters of the head (Figs 1 and 2). The tail was long and presented a well distinguishable midpiece (thicker part of the tail) (Fig. 1). The mean dimensions of the spermatozoa were: head length, $7.49 \pm 0.24 \mu \mathrm{m}$; head width, $3.53 \pm 0.19 \mu \mathrm{m}$; head thickness, $1.61 \pm 0.13 \mu \mathrm{m}$; midpiece length, $11.36 \pm 0.34 \mu \mathrm{m}$; flagellum length, $40.91 \pm 1.94 \mu \mathrm{m}$; total tail length, $52.16 \pm 1.06$ $\mu \mathrm{m}$; and total spermatozoon length, $60.08 \pm 1.40 \mu \mathrm{m}$.

In the transmission electron microscopy analysis, the nucleus was composed of a compact mass of homogeneously distributed electron dense chromatin with small vacuoles (Figs 3-6), with the base thicker than the upper part (Figs 4 and 5), and a concave recess for tail insertion (Fig. 6). The acrosome covered most of the head, being swollen and irregular in shape (Fig. 3). The neck was characterized as a region without mitochondria, in which coarse fibers were present binding the head to the tail (Fig. 6). The tail was divided into midpiece and flagellum. Axoneme fibers, organized as a central pair surrounded by nine pairs of fibers (Fig. 11), and coarse fibers, characterized as electron dense structures around the axoneme (Fig. 7), were present along the tail. The midpiece showed the mitochondrial helix around the tail fibers (Figs 7-9). The flagellum was characterized by the presence of a fibrous helix (two continuous fiber columns connected by circumferential bands) around the tail fibers (Figs 9-11). The shape and size of the coarse fibers varied along the midpiece and became thinner along the flagellum (Figs 7, 8 and 11). The plasmatic membrane appeared absent or damaged along the tail (Figs 9 and 11).

The shape of Amazonian manatee spermatozoon was similar to other sirenian spermatozoa previously described, such as the Florida manatee Trichechus manatus latirostris (Harlan, 1824) (Miller et al. 2001) and dugong Dugong dugon (Müller, 1776) (MARSH et al. 1984). However, the Amazonian manatee spermatozoon is 2-fold bigger in total length than that of the Florida manatee $(30.1 \mu \mathrm{m}$; Miller et al. 2001), but a little bit smaller than the dugong spermatozoon $(65.0 \mu \mathrm{m}$; MARsh et al. 1984). Cummins \& Woodall (1985) considered that there is a negative correlation between sperm size and body mass among mammals, and maybe that can explain the differences observed. The Florida manatee weighs up to $1500 \mathrm{~kg}$ and the dugong weighs up to $400 \mathrm{~kg}$ (MuRPHy 2003), while the Amazonian manatee can weigh up to $450 \mathrm{Kg}$ (Rosas 1994). However, Florida mana-

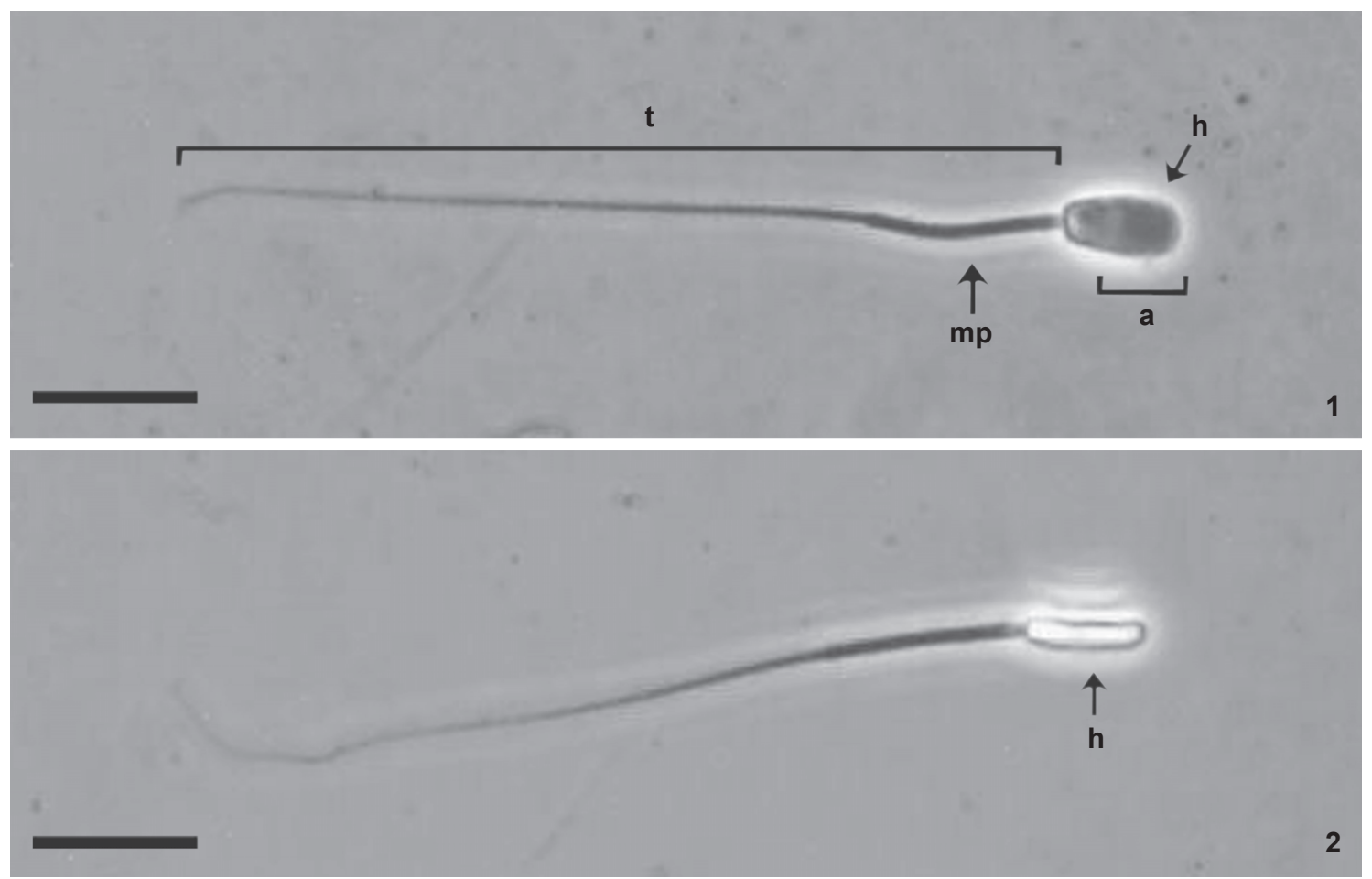

Figures 1-2. Light micrographs of T. inunguis spermatozoa in frontal view (1) and lateral view (2). (h) Head, (t) tail, (a) acrosome, (mp) midpiece. Scale bar $=10 \mu \mathrm{m}$. 


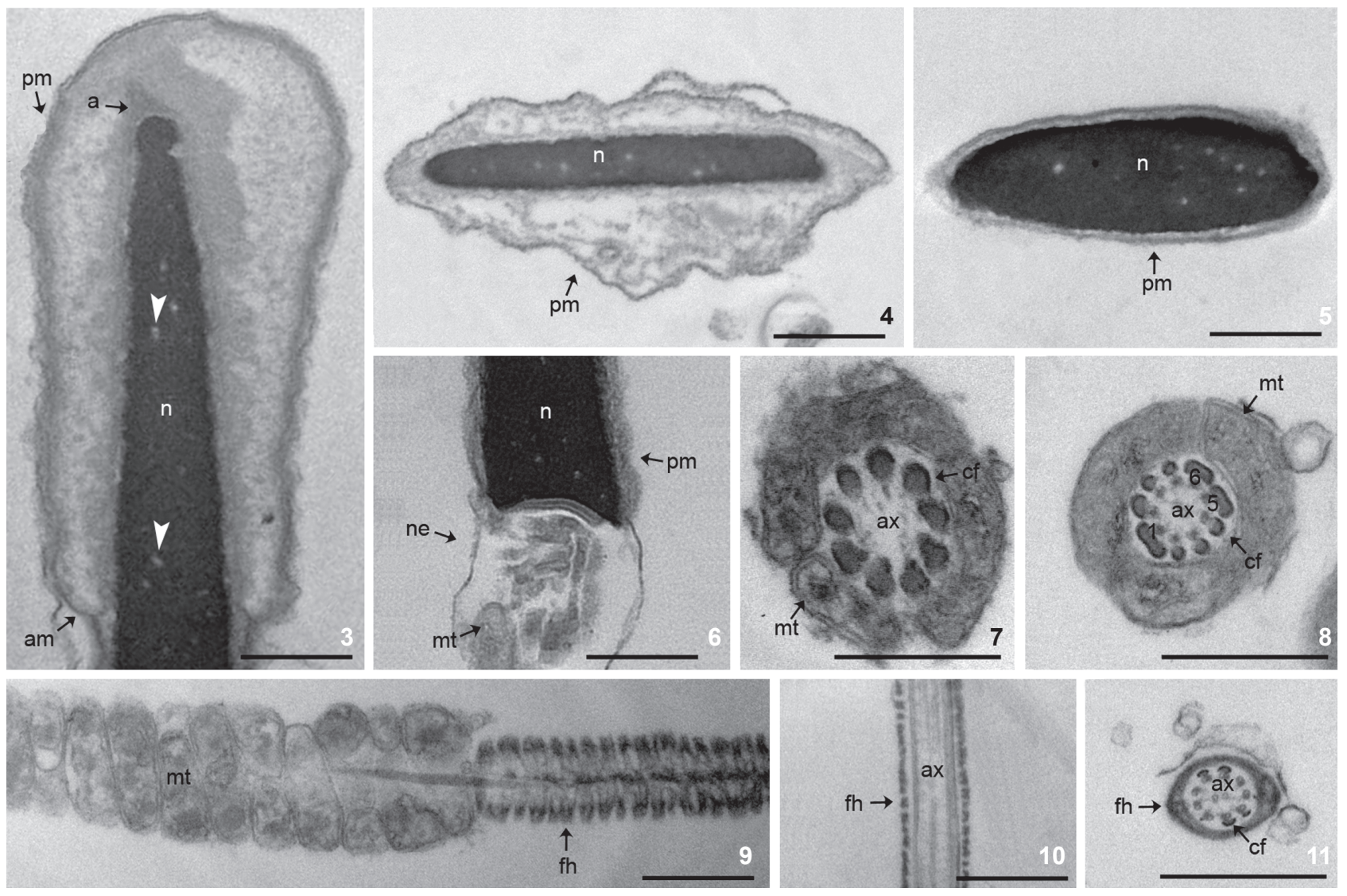

Figures 3-11. Electron micrographs of T. inunguis spermatozoa. (3) Longitudinal section of the head. (pm) plasmatic membrane; (am) acrosomal membrane; (a) acrosome; ( $n$ ) nucleus; (white arrowhead) vacuole. Note the acrosome swelling. (4-5) Transversal sections of upper portion and basal portion of the head. (mp) plasmatic membrane; (n) nucleous. (6) Diagonal section of the neck region (ne). Note the mitochondria marking the beginning of the tail. (7-8) Transversal sections of the cranial and caudal portion of midpiece. Note the difference of size and shape of the coarse fibers (cf). (ax) axoneme; (mt) mitochondria. (9) Tangential section of the tail at the transition region from midpiece to flagellum. (mt) mitochondria; (fh) fibrous helix. Note the absence of plasmatic membrane. (10-11) Longitudinal and transversal sections of the flagellum. (ax) Axoneme, (fh) fibrous helix, (cf) coarse fibers. Scale bar $=0.5 \mu \mathrm{m}$.

tee spermatozoa described by MiLler et al. (2001), also obtained from a single male, were measured using scanning electron microscopy images, thus that size difference needs to be evaluated with caution.

In general, the ultrastructure of Amazonian and Florida manatees' spermatozoa were similar. However, MilLer et al. (2001) reported that $T$. $m$. latirostris spermatozoa show a very pronounced annulus, and this structure was not observed in $T$. inunguis. On the other hand, the alterations observed (swelling and irregular shape of acrosome and the disruption or loss of plasmatic membrane) probably are post-mortem degeneration due to osmotic stress by the urine (VIJAYAKUMar et al. 1986, Griggers et al. 2001). Therefore, the annulus from Amazonian manatee spermatozoa might have been lost. There is no report about dugong spermatozoa ultrastructure to be compared with
Amazonian manatee spermatozoa.

This is the first report describing the morphology, morphometry and ultrastructure of Amazonian manatee spermatozoa. Although our data are from one individual, apparently there are morphometric differences among sirenians spermatozoa. This study also shows that morphological analysis of spermatozoa retrieved from urine samples can be a useful tool in biological studies.

\section{ACKNOWLEDGEMENTS}

We thank CNPq, Programa Petrobras Ambiental and Associação Amigos do Peixe-boi (AMPA) for financial support; PREVET staff for help with sample collection and Renata C. Silva for help with microscopic analysis. 


\section{LITERATURE CITED}

Anderson, M.J.; J. Nyholt \& A.F. Dixton. 2005. Sperm competition and the evolution of sperm midpiece volume in mammals. Journal of Zoology 267 (2): 135-142. doi: 10.1017/ S0952836905007284.

BEST, R.C. 1984. The aquatic mammals and reptiles of the Amazon, p. 371-412. In: H. SIOLI (Ed.). The Amazon, limnology and landscape ecology of a mighty tropical river and its basin. Dordhecht, Dr. W. Junk Publishers, 761p.

Cummins, J.M. \& P.F. Woodall. 1985. On mammalian sperm dimensions. Journal of Reproduction and Fertility 75: 153 175. doi: 10.1530/jrf.0.0750153.

Griggers, S.; D.L. Paccamonti; R.A. Thompson \& B.E. Eilts. 2001. The effects of $\mathrm{pH}$, osmolarity and urine contamination on equine spermatozoal motility. Theriogenology 56 (4): 613622. doi: 10.1016/S0093-691X(01)00593-3.

Husar, S.L. 1977. Trichechus inunguis. Mammalian Species 72 (1): $1-4$

Luque, M.C.A. \& S.N. BÁo. 2006. Structural and ultrastructural characterization of zebu (Bos indicus) spermatozoa. Biocell 30 (1): 33-38.

Marsh, H.; G.E. Heinsohn \& T.D. Glover. 1984. Changes in the male reproductive organs of the dugong, Dugong dugon (Sirenia: Dugondidae) with age and reproductive activity. Australian Journal of Zoology 32 (6): 721-742. doi: 10.1071/ZO9840721.

Miller, D.L.; M.M. Dougherty; S.J. Decker \& G.D. Bossart. 2001. Ultrastructure of the spermatozoa from a Florida manatee (Trichechus manatus latirostris). Anatomia, Histologia, Embryologia 30 (4): 253-256. doi: 10.1046/j.1439-0264. 2001.00330.x.

Murphy, D. 2003. Sirenia, p. 476-482. In: M.E. Fowler \& R.E. Miller (Ed.). Zoo and Wildlife Animal Medicine. Philadelphia, W. B. Saunders Co., 992p.

Plön, S. \& R.T.F. BERnard. 2006. A review of spermatozoan morphology in Cetacea with new data for the genus Kogia. Journal of Zoology 269 (4): 466-473. doi: 10.1111/j.14697998.2006.00061.x.

Rosas, F.C.W. 1994. Biology, conservation and status of the Amazonian manatee Trichechus inunguis. Mammal Review 24 (2): 49-59. doi: 10.1111/j.1365-2907.1994.tb00134.x.

Vijayakumar, R.; O. Usun; R. Swope; F. De Leon \& W. Heine. 1986. Fine structure of spermatozoa retrieved from retrograde ejaculates. Systems Biology in Reproductive Medicine 17 (1): 25-33.

Submitted: 22.VII.2010; Accepted: 25.IX.2010.

Editorial responsibility: Carolina Arruda Freire 